\title{
31ST INTERNATIONAL CONFERENCE ON COORDINATION CHEMISTRY
}

\section{The University of British Columbia, Vancouver, Canada August 18-23, 1996}

\author{
ORGANIZING COMMITTEE
}

Chris Orvig, University of British Columbia, Chairman

Ross Hill, Simon Fraser University, Secretary

Rowena Tate, UBC Conference Centre, Conference Manager

\section{PROGRAMME COMMITTEE}

William R. Cullen, University of British Columbia

Michael D. Fryzuk, University of British Columbia

Ross Hill, Simon Fraser University

Brian R. James, University of British Columbia

A.D. Kirk, University of Victoria

Peter Legzdins, University of British Columbia

Alex McAuley, University of Victoria

Chris Orvig, University of British Columbia

Derek Sutton, Simon Fraser University

\section{SCIENTIFIC PROGRAMME}

Plenary Lecturers

Prof. C. David Garner, University of Manchester, UK; "X-ray Absorption Spectroscopic Studies of Metal Centres in Biology and Developments of Relevant Synthetic Analogues"

Prof. Brian R. James, University of British Columbia, Canada; "Coordination Chemistry, and Catalytic Conversions, of Hydrogen Sulfide"

Prof. Eiichi Kimura, Hiroshima University School of Medicine, Japan; "Macrocyclic Metal Complexes for Selective Recognition of Nucleic Acid Bases and Manipulation of Gene Expression"

Prof. Walter G. Klemperer, University of Illinois, USA; “Self-Assembled Inorganic Monolayers: Coordination Chemistry in Two Dimensions"

Prof. Leonard F. Lindoy, James Cook University, Australia; "Tailoring Macrocycles and Molecular Assemblies for Metal Ion Binding"

Prof. Richard R. Schrock, Massachusetts Institute of Technology, USA; "High Oxidation State Coordination Chemistry with Triamidoamine Tungsten and Molybdenum Complexes" 


\section{Session Lecturers}

There will be nine sessions covering all aspects of coordination chemistry; session lecturers are as follows (as of the time of printing):

\section{Metal Centres in Biology and Medicine}

Dr. Michael Abrams, Johnson-Matthey, Inc., USA; "Ruthenium Complex Scavenging of Nitric Oxide in Biological Systems"

Prof. Peter J. Sadler, Birkbeck College, University of London, UK; "Metallodrugs: Design and Mechanism of Action"

Prof. Dr. Dieter Sellman, Universität Erlangen-Nürnberg, Germany; "Biological Challenges to Coordination Chemistry: Modelling the Reactivity of Nitrogenase and Other Metal Sulfur Enzymes"

Prof. Edward I. Solomon, Stanford University, USA; "Electronic Structure of the Blue Copper Active Site: Contributions to Electron Transfer Reactivity"

\section{Mechanistic Insights}

Prof. James H. Espenson, Iowa State University, USA; "Mechanisms of Reactions Catalyzed by Methylrhenium Trioxide"

Prof. Hitoshi Ohtaki, Ritsumeikan University, Japan; "Structure of Intermediates in the Metal Substitution Reactions of the Mercury(II)-Porphyrin Complex with Divalent Transition Metals Determined by the StoppedFlow-EXAFS Method"

Dr. Joop A. Peters, Delft University of Technology, The Netherlands; "Solution Structures of Lanthanide Chelates"

Prof. Alexander D. Ryabov, M. V. Lomonosov Moscow State University, Russia; "Mechanisms of Enzymatic Reactions of Ferrocene Derivatives"

Prof. Thomas W. Swaddle, University of Calgary, Canada; "Understanding Pressure Effects in the Solution Chemistry of Coordination Compounds"

\section{Activation of Small Molecules}

Prof. Pierre Braunstein, Université Louis Pasteur, France; "Bimetallic Synthesis and Reactivity"

Prof. Ernesto Carmona, Universidad de Sevilla - CSIC, Spain; "Rhodium and Iridium Mediated C-C Bond Forming Reactions Involving Small, Unsaturated Organic Molecules"

Prof. Juan Costamagna, University of Santiago, Chile; "Complexes with Aza-macrocyclic Ligands Active for the Reduction of Carbon Dioxide"

Prof. William B. Tolman, University of Minnesota, USA; "Binding and Activation of Dioxygen and Nitrogen Oxides by Copper Complexes: Relevance to Biological Catalysis"

Prof. Joan S. Valentine, University of California at Los Angeles, USA; "Defining Possible Mechanisms for Enzymatic Dioxygen Activation by Studying Reactions of Transition Metal Complexes"

\section{New Materials}

Prof. Mark P. Andrews, McGill University, Canada; "Coordinating Molecules and Mesoscopic Structures for Optical Devices"

Prof. Michael J. Sailor, University of California at San Diego, USA; "Chemistry at the Surface of Luminescent Porous Silicon"

Dr. Lynn Schneemeyer, AT \& T Bell Laboratories, USA "Chemistry of Solids"

Prof. Samuel I. Stupp, University of Illinois, USA: "Self-Assembly of Molecular and Composite Materials 


\section{Multidentate Ligands and Supramolecular Assemblies}

Dr. Paul Beer, University of Oxford, UK; "Cation and Anion Coordination Chemistry of Redox- and Photoactive Ligand Systems"

Prof. Makota Fujita, Chiba University, Japan; "SelfAssembling Supramolecular Complexes: From Macrocycles to Catenanes"

Prof. Stephen Lincoln, University of Adelaide, Australia; "Pendant Arm Macrocyclic Ligand Complexes" Prof. Vincent L. Pecoraro, University of Michigan, USA; "Metallacrowns: New Inorganic Molecular Recognition Agents"

\section{Electronic Properties: Theory and Practice}

Prof. Odile Eisenstein, Université de Paris-Sud, France; "An Ab Initio Calculation of the NMR ${ }^{1} \mathrm{H}$ Quantum Exchange in the Case of Osmium Hydride Complexes"

Prof. Olivier Khan, Institut Universitaire de France; "Molecular Magnetism: a New Challenge for Coordination Chemists"

Prof. A. B. P. Lever, York University, Canada: "Electrochemical Parameterization: Theory, and Application to Organometallic Species"

Prof. Per E. M. Siegbahn, University of Stockholm, Sweden; "Theoretical Transition Metal Chemistry: Methods, Models and Results"

\section{Environmental Chemistry: Initiatives and Applications}

Dr. O. F. X. Donnard, Université de Bordeaux 1, France; "Environmental Aspects of the Biogeochemistry of Sn, Se and As in Marine Ecosystems"

Dr. Donald S. Gamble, Agriculture Canada; "Discrete Site Complexes On Humic Polyelectrolytes: The Frontier of Coordination Chemistry"

Prof. Stalfan Sjoberg, University of Umea, Sweden; "Surface Complexation Models for Sorption at the Mineral - Water Interface"

Prof. Dr. Rudy van Eldik, Universität ErlangenNurnberg, Germany; “Metal-catalyzed Oxidation of S(IV) - A Challenge to Coordination Chemists"

\section{Main Group Chemistry}

Prof. Andrew R. Barron, Rice University, USA; “Aluminum, Gallium and Indium Complexes of Group 16 Donor Ligands"

Prof. Phillip P. Power, University of California at Davis, USA; "Multiple Bonding and Steric Effects in the Main Group 3 Elements"

Prof. Dr. Hubert Schmidbaur, Technische Universität Munchen, Germany; "Metalloids in Multinuclear Metallo Complexes"

Prof. James D. Wuest, Université de Montréal, Canada; “Coordination Chemistry of Multidentate Lewis Acids"

9. Advances in Molecular Structure and Design

Prof. C. C. (Kit) Cummins, Massachusetts Institute of Technology, USA; "Reactions of Three-Coordinate Transition Metal Complexes with Small Molecules and Related Substrates"

Prof. Kim R. Dunbar, Michigan State University, USA; "Ordered Arrays of Metals With Polynitrile or Cyanide Ligands"”

Prof. Dr. F. Ekkehardt Hahn, Freie Universitat Berlin, Germany; "Ligands with Subvalent Group 14 Donor Atoms: Multidentate Isocyanides, Carbenes, and Stannylenes"

Dr. Maurizio Peruzzini, ISSECC CNR, Italy; "Synthesis of Aminophosphine Ligands and Their Organometallic Chemistry in Combination with Transition Metals" 
Poster Sessions and Short Lectures

Poster sessions and 20-minute lectures will be culled from the submitted abstracts. These will also be divided into the nine session topics listed above.

More information can be obtained from the Conference Secretariat

\author{
31st ICCC Secretariat \\ UBC Conference Centre \\ 5961 Student Union Boulevard \\ Vancouver, B.C. Canada V6T 2C9
}

Telephone: 1 (604) 822-1050

Facsimile: 1 (604) 822-1069

E-mail: registration @ brock.housing.ubc.ca

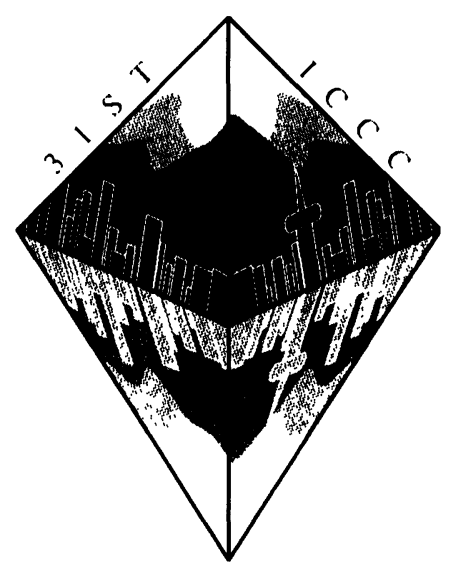

